\title{
Microbial Transformation of Selected Flavanones as a Method of Increasing the Antioxidant Properties
}

\author{
Edyta Kostrzewa-Susłow*, Jadwiga Dmochowska-Gładysz, and Tomasz Janeczko \\ Department of Chemistry, Wrocław University of Environmental and Life Sciences, \\ Norwida 25, 50-375 Wrocław, Poland. Fax: +48-71-3284124. \\ E-mail: edyta.kostrzewa-suslow@up.wroc.pl \\ * Author for correspondence and reprint requests \\ Z. Naturforsch. 65 c, 55-60 (2010); received August 6/September 17, 2009
}

Antioxidant properties of substrates [flavanone (1), 6-hydroxy- (2), 7-hydroxy- (3), 5,7,4'trihydroxy- (5), and 7-methoxyflavanone (4)] and products of their microbial transformations, comprising hydroxylation, $O$-methylation, stereospecific reduction, dehydrogenation, and C-ring cleavage of the benzo- $\gamma$-pyrone system, were determined. Measurements of the antiradical activity (expressed as $\mathrm{IC}_{50}$ value) of both the substrates and the products led to the determination of the impact of type and location of substituents in the tested flavonoids on changes in their antioxidant activities.

Key words: Biotransformation, Antioxidant Activity, Flavonoids

\section{Introduction}

Flavonoids are one of the largest groups of secondary metabolites, commonly found in plants. The preventive and therapeutic efficiency of flavonoids arise mainly from their antioxidant activities: elimination of the active form of oxygen and nitrogen, effective inhibition of lipids' oxidation, capacity of inhibition of numerous enzymes, and ability to bind metal cations, which stimulate free radical processes (Bagchi et al., 1997; Boveris and Puntarulo, 1998; Di Carlo et al., 1999; Gao et al., 1998; Rice-Evans et al., 1997; Verstraeten et al., 2002). Since several years antioxidant properties of flavonoids are in the centre of interest of many research institutes. This interest aims at finding natural antioxidants, which would protect an organism from harmful effects of free radicals and other forms of active oxygen. Attention is directed to a possibility of employment of antioxidants, including flavonoids, in food so as to increase the usability period, and also in nutraceutics (Aisling Aherne and O'Brien, 2002). The main effort is focused to find a correlation between a flavonoid compound structure and its antioxidant activity (Bors et al., 1990; Rice-Evans et al., 1996). Microbial transformations, via modification of the substrate structure, may increase the antioxidant properties of both natural flavonoids isolated from plants and synthetic flavonoid compounds.

\section{Material and Methods}

Analysis

The course of microbial transformation was monitored by TLC $\left(\mathrm{SiO}_{2}\right.$, DC Alufolien Kieselgel $60 \mathrm{~F}_{254}$, Merck, Darmstadt, Germany). Chromatograms were developed using the following developing systems: hexane/ethyl acetate (7:3), dichloromethane/ethyl acetate (1:1), toluene/diethyl ether (4:1). Column chromatography $\left(\mathrm{SiO}_{2}\right.$, Kieselgel 60, 230-400 mesh, 40-63 $\mu$ m, Merck) was performed using the same eluents. ${ }^{1} \mathrm{H}$ NMR and ${ }^{13} \mathrm{C}$ NMR spectra were recorded on a Bruker Avance DRX 300 spectrometer. IR spectra were determined on a Mattson IR 300 Thermo Nicolet spectrometer. Optical rotations were measured on an Autopol IV automatic polarimeter Rudolph (Garforth, UK). HPLC analysis was performed on a Waters 2690 instrument with a Waters 996 photodiode array detector, equipped with an ODS 2 column $(4.6 \times 250 \mathrm{~mm}$, Waters $)$ and a Guard-Pak Inserts $\mu$ Bondapak C18 pre-column. Separation conditions were as follows: gradient elution using $80 \%$ of acetonitrile in $4.5 \%$ formic acid (eluent A) and $4.5 \%$ formic acid (eluent B); flow, $1 \mathrm{ml} /$ min; detection wavelength, $280 \mathrm{~nm}$; program: $0-7 \mathrm{~min}, 10 \% \mathrm{~A} / 90 \% \mathrm{~B} ; 7-10 \mathrm{~min}, 50 \% \mathrm{~A} / 50 \%$ B; $10-13 \mathrm{~min}, 60 \% \mathrm{~A} / 40 \% \mathrm{~B} ; 13-15 \mathrm{~min}, 70 \%$ $\mathrm{A} / 30 \% \mathrm{~B} ; 15-20 \mathrm{~min}, 80 \% \mathrm{~A} / 20 \% \mathrm{~B} ; 20-30 \mathrm{~min}$, $90 \%$ A $/ 10 \%$ B; 30-40 min, 100\% A. Enantiomeric 
excess was determined using a Chiralpak AD-H HPLC column $(4.6 \times 250 \mathrm{~mm}$, Diacel $)$, with hexane/isopropanol $(9: 1)$ as eluent (isocratic resolution). Antioxidant properties were measured on a Cintra 20 spectrometer (GBC, Melbourne, Australia).

\section{Materials}

The reacemic substrates for biotransformation, flavanone (1), 6-hydroxyflavanone (2), 7-hydroxyflavanone (3), 7-methoxyflavanone (4), and 5,7,4'-trihydroxyflavanone (5) (Fig. 1), were purchased from Aldrich.

\section{Screening procedure}

Cultivation media consisted of $3 \%$ glucose and $1 \%$ peptobac in water. The microorganisms were transferred from the slants to 250-ml Erlenmeyer flasks, each containing $100 \mathrm{ml}$ of the medium. Preincubation was performed at $25^{\circ} \mathrm{C}$ for $24-48 \mathrm{~h}$, until the proper growth of the microorganisms was achieved. Then portions of $1 \mathrm{ml}$ of the culture solution were transferred into 250 -ml flasks, each containing $100 \mathrm{ml}$ of the medium. After cultivation at $25^{\circ} \mathrm{C}$ for $48 \mathrm{~h}$ on a rotary shaker, $10 \mathrm{mg}$ of a substrate, dissolved in $0.5 \mathrm{ml}$ of acetone, were added to the grown culture. Control cultivation with no substrate was also performed. After 1, 3,6 and $9 \mathrm{~d}$ of incubation under the above conditions, portions of $5 \mathrm{ml}$ of the transformation mixture were taken out and extracted with ethyl acetate $(3 \times 3 \mathrm{ml})$. The extracts were dried over $\mathrm{MgSO}_{4}$, concentrated in vacuo, and analyzed by
TLC. Quantitative analyses of the mixtures were performed by means of HPLC. Calibration curves for quantitative analyses were prepared using isolated and purified biotransformation products as standards.

\section{Preparative biotransformation}

Portions of $1 \mathrm{ml}$ of the pre-incubation culture solution were used to inoculate three 2000-ml flasks, each containing $500 \mathrm{ml}$ of the cultivation medium. The cultures were incubated at $25^{\circ} \mathrm{C}$ for $48 \mathrm{~h}$ on a rotary shaker. Then $50 \mathrm{mg}$ of a substrate dissolved in $2.5 \mathrm{ml}$ of acetone were added to each flask (100 mg of the substrate per 11 of the cultivation mixture). After $9 \mathrm{~d}$ of incubation the mixtures were extracted with ethyl acetate $(3 \times 200 \mathrm{ml})$, dried $\left(\mathrm{MgSO}_{4}\right)$, and concentrated in vacuo. The transformation products were separated by column chromatography. Pure products were identified by means of spectral analyses (TLC, ${ }^{1} \mathrm{H}$ NMR, ${ }^{13} \mathrm{C}$ NMR, IR) and optical rotation measurements (Kostrzewa-Susłow et al., 2006a, b, 2008).

\section{Measurement of antioxidant properties of the substrates and products}

A methanolic solution of DPPH (1,1-diphenyl2-picryl-hydrazyl) of absorbance of about 1.00, was mixed with a proper amount of a tested flavonoid. After $20 \mathrm{~min}$, disappearance of the absorbance at $520 \mathrm{~nm}$ was measured. The initial concentration of DPPH was determined by means of a calibration curve. The $\mathrm{IC}_{50}$ value (antiradical activity) was de-<smiles>COC1CC(c2ccccc2)Oc2ccccc21</smiles><smiles>O=C1CC(c2ccccc2)Oc2ccc(O)cc21</smiles><smiles>O=C1CC(c2ccccc2)Oc2cc(O)ccc21</smiles><smiles>COc1ccc2c(c1)OC(c1ccccc1)CC2=O</smiles><smiles>O=C1CC(c2ccc(O)cc2)Oc2cc(O)cc(O)c21</smiles>

Fig. 1. Flavanones subjected to microbial transformations: flavanone (1), 6-hydroxyflavanone (2), 7-hydroxyflavanone (3), 7-methoxyflavanone (4), 5,7,4'-trihydroxyflavanone (5). 
termined on the basis of graphs - DPPH radical reduction (expressed in \%) as a function of concentration of the tested compound. $\mathrm{IC}_{50}$ means concentration of the antioxidant that reduces the initial concentration of DPPH by half.

\section{Results and Discussion}

In our previous papers we presented screening tests on 27 microorganisms, leading to the selection of strains of Aspergillus and Penicillium, which catalyze reactions of hydroxylation, $O$-methylation, stereospecific reduction, dehydrogenation and C-ring cleavage of the benzo[r]pyrone system in flavanone (1) and its methoxyand hydroxy derivatives $\mathbf{2}-\mathbf{5}$ (Fig. 1). Full spectroscopic analysis $\left({ }^{1} \mathrm{H}\right.$ NMR, ${ }^{13} \mathrm{C}$ NMR, IR) of the isolated biotransformation products was performed and, in four cases, X-ray analysis as well (Kostrzewa-Susłow et al., 2006a, b, 2008; Białońska et al., 2007a, b). The next stage of the study was assessment of antioxidant properties of the substrates and the products obtained by means of the DPPH radical in order to find a correlation between type and location of functional groups in the flavonoid and its antioxidant activity. $\mathrm{IC}_{50}$ values of flavonoid substrates and products of their biotransformations are shown in Table I, and the structures of selected biotransformation products are presented in Fig. 2. The $\mathrm{IC}_{50}$ values of the flavonoids shown in Table I allow to assess an impact of structural differences on the antioxidant activity. Comparison of the $\mathrm{IC}_{50}$ values proves that seven out of nine biotransformation products of flavanone (1) have higher antioxidant activity than the substrate. Among them, the highest antioxidant activity $\left(\mathrm{IC}_{50}=8.00 \mu \mathrm{M}\right)$ is attributed to 4,2'-dihydroxydihydrochalcone (6) (Fig. 2), followed by 2',5'-dihydroxydihydrochalcone (7) $\left(\mathrm{IC}_{50}=8.15 \mu \mathrm{M}\right)$. Among the dihydrochalcone products the highest $\mathrm{IC}_{50}$ value (and

Table I. The $\mathrm{IC}_{50}$ values of the flavonoid substrates and the biotransformation products.

\begin{tabular}{|c|c|c|}
\hline Substrate & Product & $\mathrm{IC}_{50}[\mu \mathrm{M}]$ \\
\hline Flavanone (1) & $\begin{array}{l}\text { 4,2'-Dihydroxydihydrochalcone }(\mathbf{6}) \\
\text { 2',5'-Dihydroxydihydrochalcone }(\mathbf{7}) \\
\text { 6-Hydroxyflavanone }(\mathbf{2}) \\
\text { 3-Hydroxyflavone }(\mathbf{8}) \\
\text { 2,4-cis-7-Hydroxyflavan-4-ol }(\mathbf{9}) \\
\text { 2'-Hydroxydihydrochalcone }(\mathbf{1 0}) \\
\text { 4'-Hydroxyflavanone }(\mathbf{1 1}) \\
\text { 2,4-cis-Flavan-4-ol }(\mathbf{1 2}) \\
\text { Flavone }(\mathbf{1 3})\end{array}$ & $\begin{array}{r}9.42 \\
8.00 \\
8.15 \\
8.31 \\
9.09 \\
9.16 \\
9.17 \\
9.27 \\
9.85 \\
10.16\end{array}$ \\
\hline 6-Hydroxyflavanone (2) & $\begin{array}{l}\text { 2,4-trans-6,7,4'-Trihydroxyflavan-4-ol (14) } \\
\text { 6,4'-Dihydroxyflavanone (15) } \\
\text { 2,4-cis-6-Hydroxyflavan-4-ol (16) } \\
\text { 6-Hydroxyflavone }(\mathbf{1 7})\end{array}$ & $\begin{array}{l}8.33 \\
6.68 \\
7.55 \\
7.80 \\
9.46\end{array}$ \\
\hline 7-Hydroxyflavanone (3) & $\begin{array}{l}\text { 3',4'-Dihydroxy-7-methoxyflavanone }(\mathbf{1 8}) \\
\text { 2,4-trans-5,7-Dihydroxyflavan-4-ol (19) } \\
\text { 7-Hydroxyflavone }(\mathbf{2 0}) \\
\text { 2,4-cis-7-Hydroxyflavan-4-ol (9) } \\
\text { 7-Methoxyflavanone }(\mathbf{4})\end{array}$ & $\begin{array}{l}9.44 \\
6.70 \\
7.07 \\
8.80 \\
9.17 \\
9.50 \\
\end{array}$ \\
\hline 7-Methoxyflavanone (4) & $\begin{array}{l}\text { 4'-Hydroxy-7-methoxyflavone }(\mathbf{2 1}) \\
\text { 4,2'-Dihydroxy-4'-methoxydihydrochalcone (22) } \\
\text { 2,4-cis-7-Methoxyflavan-4-ol } \mathbf{( 2 3 )} \\
\text { 2,4-trans-7-Methoxyflavan-4-ol }(\mathbf{2 4})\end{array}$ & $\begin{array}{l}9.50 \\
7.66 \\
7.75 \\
8.20 \\
8.42\end{array}$ \\
\hline 5,7,4'-Trihydroxyflavanone (5) & 5,7,4'-Trihydroxyflavone (25) & $\begin{array}{l}7.94 \\
7.10\end{array}$ \\
\hline
\end{tabular}




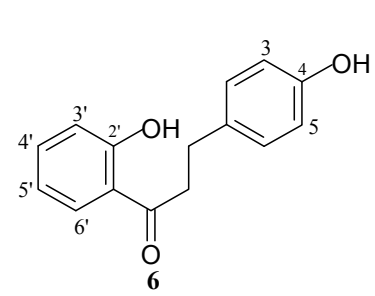<smiles>Oc1ccc([C@@H]2C[C@H](O)c3cc(O)c(O)cc3O2)cc1</smiles><smiles>COc1ccc2c(c1)OC(c1ccc(O)c(O)c1)CC2=O</smiles><smiles>COc1ccc2c(c1)O[C@@H](c1ccccc1)C[C@@H]2O</smiles><smiles>O=c1cc(-c2ccc(O)cc2)oc2cc(O)cc(O)c12</smiles>

Fig. 2. Selected products of microbial transformations of flavanones: 4,2'-dihydroxydihydrochalcone (6), 2,4-trans6,7,4'-trihydroxyflavan-4-ol (14), 3',4'-dihydroxy-7-methoxyflavanone (18), 2,4-cis-7-methoxyflavan-4-ol (23), 5,7,4'trihydroxyflavone $(\mathbf{2 5})$.

therefore the lowest antioxidant activity) was observed for 2'-hydroxydihydrochalcone (10). This leads to the conclusion, that C-ring cleavage of $\mathbf{1}$ slightly increases the antioxidant activity. As far as the products with the dihydrochalcone system are concerned, the most important factor for the increase in antioxidant activity is the position of hydroxylation. Among the dihydrochalcone products obtained, the most advantegous is that with hydroxylation at $\mathrm{C} 4$. In the case of the products which retained the benzo[ $\gamma]$ pyrone system, i.e. 6-hydroxyflavanone (2) $\left(\mathrm{IC}_{50}=8.31 \mu \mathrm{M}\right)$ and 4'hydroxyflavanone $(\mathbf{1 1})\left(\mathrm{IC}_{50}=9.27 \mu \mathrm{M}\right)$, the position of hydroxylation is also very important for increasing their antioxidant properties. The highest increase in these properties was observed in the case of C6 hydroxylation of flavanone (1). Introduction of a double bond between $\mathrm{C} 2$ and C3 of flavanone (1) considerably decreased the antioxidant activity, yielding an $\mathrm{IC}_{50}$ value of $10.16 \mu \mathrm{M}$ for 13. However, dehydrogenation of the $\mathrm{C} 2, \mathrm{C} 3$ bond combined with hydroxylation at $\mathrm{C} 3$ resulted in decreasing the $\mathrm{IC}_{50}$ value from $9.42 \mu \mathrm{M}$ for the substrate flavanone (1) to $9.09 \mu \mathrm{M}$ for 3-hydroxyflavone (8). The presence of a hydroxy group adjacent to the carbonyl moiety in 3-hydroxyflavone (8) additionally influences its capability of chelating metal ions, which are known to catalyze oxidation processes. Reduction of the carbonyl group of $\mathbf{1}$ resulted in a decrease of the antioxidant properties in the case of 2,4- cis-flavan-4-ol (12), whereas introduction of an additional hydroxy group at $\mathrm{C} 7$ led to an increase in the antioxidant activity of formed 2,4-cis-7-hydroxyflavan-4-ol (9) compared to substrate 1 and to 2,4-cis-flavan-4-ol (12). Comparison of the $\mathrm{IC}_{50}$ values of both products - $\mathbf{9}$ and $\mathbf{1 2}$ - leads to the assumption that the presence of a hydroxy group at $\mathrm{C} 7$ in product 9 is essential for increasing the antioxidant properties.

Comparison of the $\mathrm{IC}_{50}$ values of the next substrate - 6-hydroxyflavanone (2) - and products of its biotransformation indicates that among the products obtained three of them are characterized with higher antioxidant properties than $\mathbf{2}$ (Table I). Introduction of the C2,C3 double bond decreased the antioxidant activity of product $\mathbf{1 7}$. Among the products obtained the highest antioxidant activity was observed for 2,4-trans-6,7,4'trihydroxyflavan-4-ol (14) $\left(\mathrm{IC}_{50}=6.68 \mu \mathrm{M}\right)$. This increase in the antioxidant activity compared to substrate $2\left(\mathrm{IC}_{50}=8.33 \mu \mathrm{M}\right)$ is directly attributed to the presence of three new hydroxy groups in the molecule at C4, C7 and C4' (Fig. 2). Additionally, ortho configuration of the hydroxy groups (at C6, C7) in $\mathbf{1 4}$ may facilitate chelating of metal ions. As far as the rest of the biotransformation products is concerned, there are hydroxylation in the B-ring (in 15) and carbonyl group reduction (in 16) that are responsible for the increase in their antioxidant activity. 
Microbial transformations of 7-hydroxyflavanone (3) led to four products of increased antioxidant activity compared to the substrate. The most active was 3',4'-dihydroxy-7-methoxyflavanone (18) $\left(\mathrm{IC}_{50}=6.70 \mu \mathrm{M}\right)$ (Table I). This is ascribed to the presence of ortho hydroxy groups in the B-ring, which may facilitate chelation of metal ions. A considerable impact on the increase in antioxidant properties of the biotransformation products of $\mathbf{3}$ has the reduction of the carbonyl group combined with hydroxylation at C5, leading to 2,4-trans-5,7-dihydroxyflavan-4-ol (19) $\left(\mathrm{IC}_{50}=7.07 \mu \mathrm{M}\right)$. The product of reduction of the carbonyl group with no hydroxylation at $\mathrm{C} 5$, 2,4-cis-7-hydroxyflavan-4-ol (9), was less active than 19. Dehydrogenation between $\mathrm{C} 2$ and $\mathrm{C} 3$ of 7-hydroxyflavanone $(3)$ resulted in a decrease in $\mathrm{IC}_{50}$ from $9.44 \mu \mathrm{M}$ for 3 to $8.80 \mu \mathrm{M}$ for 7-hydroxyflavone (20).

Among the products of microbial transformation of 7-methoxyflavanone (4), the highest antioxidant properties were observed for 4'hydroxy-7-methoxyflavone $(\mathbf{2 1})\left(\mathrm{IC}_{50}=7.66 \mu \mathrm{M}\right)$ and 4,2'-dihydroxy-4'-methoxydihydrochalcone (22) $\left(\mathrm{IC}_{50}=7.75 \mu \mathrm{M}\right)$. Among the dihydrochalcone products $6,7, \mathbf{1 0}$, and 22 the most active was 22 . Both products of reduction of the carbonyl group - 2,4-cis- (23) and 2,4-trans-7-methoxyflavan-4-ol (24) - were characterized with higher antioxidant properties than the substrate 4. Comparison of the $\mathrm{IC}_{50}$ values of $\mathbf{2 3}$ and $\mathbf{2 4}$ indicates that $\mathbf{2 3}$ is a better antioxidant $\left(\mathrm{IC}_{50}=8.20 \mu \mathrm{M}\right)$ than $\mathbf{2 4}$ (Table I). This means that the stereochemistry may effect changes in the antioxidant properties. The methoxy group at $\mathrm{C} 7$ in $\mathbf{2 3}$ (compared to the analogous product 9 with a hydroxy group at $\mathrm{C} 7$ ) effects an increase in the antioxidant acivity.

Aisling Aherne S. and O'Brien N.-M. (2002), Dietary flavonols: chemistry, food content and metabolism. Nutrition 18, 75-81.

Bagchi D., Garg A., Krohn R.-L., Bagchi M., Ttan M.X., and Stohs S.-J. (1997), Oxygen free radical scavenging abilities of vitamins $\mathrm{C}$ and $\mathrm{E}$, and a grape seed proanthocyanidine extract in vitro. Res. Commun. Mol. Pathol. Pharmacol. 95, 179-189.

Białońska A., Ciunik Z., Kostrzewa-Susłow E., and Dmochowska-Gładysz J. (2007a), Disordered 6-hydroxyflavanone. Acta Cryst. E 63, 430-431.

Białońska A., Ciunik Z., Kostrzewa-Susłow E., and Dmochowska-Gładysz J. (2007b), Disordered 4'-hydroxyflavanone. Acta Cryst. E 63, 432-433.
Biotransformation of 5,7,4'-trihydroxyflavanone (5) gave the product of dehydrogenation at $\mathrm{C} 2$ and C3-5,7,4'-trihydroxyflavone (25), which is characterized with higher antioxidant properties $\left(\mathrm{IC}_{50}=7.10 \mu \mathrm{M}\right)$ than $\mathbf{5}\left(\mathrm{IC}_{50}=7.94 \mu \mathrm{M}\right)$.

The above described structural changes in flavonoids obtained by biotransformation processes, and arising from these changes, the antioxidant properties of the products allow to draw some conclusions. Hydroxylation at C4' in the B-ring of flavanones $\mathbf{1 1}$ and $\mathbf{1 5}$ leads to the formation of products of higher antioxidant properties than the substrates. Hydroxy groups in the A-ring increase the antioxidant properties. The strongest increasing effect has a hydroxy group at C6. Reduction of carbonyl groups in mono-substituted flavanones subjected to biotransformations results in an increase in the antioxidant properties of the products (Table I). In case of non-substituted, reduced 2,4-cis-flavan-4-ol (12) the opposite process is observed. Among the hydroxylation products, higher antioxidant properties have the ones with a hydroxy group at C6 in the A-ring. Dehydrogenation at $\mathrm{C} 2, \mathrm{C} 3$ in the C-ring causes an increase in the antioxidant properties only in the case of biotransformation of 7-hydroxyflavanone (3) and 5,7,4'-trihydroxyflavanone (5). Dehydrogenation of flavanone (1) and 6-hydroxyflavanone (2) gives the opposite effect. Therefore, the presence of a double bond between $\mathrm{C} 2$ and $\mathrm{C} 3$, conjugated with the carbonyl group, is not a factor exactly effecting an increase in the antioxidant activity. This structure plays merely a secondary role. This is the presence and the location of hydroxy groups that has the strongest impact on the antioxidant properties (especially $\mathrm{OH}$ at C7 is important).

Bors W., Heller W., Michel Ch., and Saran M. (1990), Flavonoids as antioxidants: determination of radical scavenging efficiencies. Methods Enzymol. 186, 343-354.

Boveris A.-D. and Puntarulo S. (1998), Free-radical scavenging actions of natural antioxidants. Nutrition Res. 18, $1545-1557$.

Di Carlo G., Mascolo N., Izzo A.-A., and Capasso F. (1999), Flavonoids: old and new aspects of a class of natural therapeutic drugs. Life Sci. 65, 337-353.

Gao D., Tawa R., Masaki H., Okano Y., and Sakurai H. (1998), Protective effects of baicalein against damage by reactive oxygen. Chem. Pharm. Bull. 46, 1383-1387. 
Kostrzewa-Susłow E., Dmochowska-Gładysz J., Białońska A., Ciunik Z., and Rymowicz W. (2006a), Microbial transformations of flavanone and 6-hydroxyflavanone by Aspergillus niger strains. J. Mol. Catal. B: Enzym. 39, 18-23.

Kostrzewa-Susłow E., Dmochowska-Gładysz J., and Ekert A. (2006b), Transformacje mikrobiologiczne 6-hydroksyflawanonu. Flawonoidy i ich zastosowanie. Oficyna Wydawnicza Politechniki Rzeszowskiej, Rzeszów.

Kostrzewa-Susłow E., Dmochowska-Gładysz J., Białońska A., and Ciunik Z. (2008), Microbial transformations of flavanone by Aspergillus niger and
Penicillium chermesinum cultures. J. Mol. Catal. B: Enzym. 52-53, 34-39.

Rice-Evans C.-A., Miller N.-J., and Paganga G. (1996), Structure-antioxidant activity relationships of flavonoids and phenolic acids. Free Radic. Biol. Med. 20, 933-956.

Rice-Evans C.-A., Miller N.-J., and Paganga G. (1997), Antioxidant properties of phenolic compounds. Trends Plant Sci. 2, 152-159.

Verstraeten S.-V., Keen C.-L., Schmitz H.-H., Fraga C.-G., and Oteiza P.-I. (2002), Flavan-3-ols and procyanidins protect liposomes against lipid oxidation and disruption of the bilayer structure. Free Radic. Biol. Med. 34, 84-92. 